\title{
Clinical, echocardiographic, and operative findings in active infective endocarditis
}

\author{
T H PRINGLE, S W WEBB, M M KHAN, H O J O'KANE, J CLELAND, A A J ADGEY \\ From Regional Medical and Surgical Cardiology Centres, Royal Victoria Hospital, Grosvenor Road, Belfast, \\ NIreland
}

SUMMARY Clinical and echocardiographic findings were compared with those found at operation in 18 consecutive patients with active endocarditis undergoing valve replacement for continuing left ventricular failure. A close correlation was shown between vegetations detected by echocardiography and those found at operation. In 10 of 11 patients with clinically suspected severe aortic regurgitation and vegetations only on the aortic valve and in two of three patients with severe mitral regurgitation echocardiography provided confirmation of the clinical diagnosis. In the three patients with clinically suspected aortic and mitral regurgitation, however, cardiac catheterisation was necessary to confirm the severity of the valvular regurgitation. In a further three patients cardiac catheterisation was carried out as the severity of the single valve lesion was difficult to assess or there were associated problems, that is chest pain with myocardial infarction and a sinus of Valsalva aneurysm. Four patients had either an abscess, annular infection, a sinus, or a ventricular septal defect at the time of operation, which were not detected by echocardiography. Nevertheless, because of their size it would be doubtful if these would have been identified by cardiac catheterisation. Echocardiography allowed repeated assessment of the patient so that the optimal time for operation could be determined without the risks of left heart catheterisation. Fourteen of the 18 patients $(78 \%)$ survived to leave hospital. The follow-up extended to 44 months. During this time reinfection, prosthetic dehiscence, or paravalvular leaks did not occur. Thus, in the majority of patients with left sided active infective endocarditis and continuing left ventricular failure resulting from severe valvular disease the clinical findings together with echocardiography provide a satisfactory preoperative assessment.

In patients who develop haemodynamic complications of endocarditis, early surgical intervention is increasingly used. ${ }^{1-3}$ Aortic or mitral valve endocarditis complicated by moderate to severe heart failure has a poor prognosis when treated by medical therapy alone. ${ }^{4}$ It has been suggested that in these patients with moderate to severe heart failure there is a 50 to $89 \%$ mortality without operation. ${ }^{4}$ Valve replacement in the presence of active infection can now be carried out with an acceptable mortality, and in addition the risk of recurrent infection or valve dysfunction is low. ${ }^{6}$ Confirmation of the haemodynamic status and valvular lesions by cardiac catheterisation is theoretically desirable but should carry an increased risk of systemic embolisation considering the natural history of the disease. Echocardiography is a useful non-invasive means of identifying valvular vegetations but both $M$ mode and two dimensional echocardiography have a limited sensitivity in the detection of vegetations. It has

Accepted for publication 9 September 1982 been suggested that the smallest vegetations detected by $M$-mode echocardiography are $2 \mathrm{~mm}$ in diameter. ${ }^{78}$ The larger vegetations which often result in valvular destruction and regurgitation are recognised by echocardiography and it is in these patients that operation is frequently necessary. ${ }^{58} 9$ Though it is desirable to eradicate the infection before correction of the valve lesion, when uncontrolled heart failure develops during the course of antibiotic treatment, surgical correction of the valvular defect is urgent. In this study we compared the clinical and echocardiographic findings with those found at operation in patients with active endocarditis undergoing valve replacement because of continuing left ventricular failure despite digitalis and diuretics.

\section{Patients and methods}

Eighteen consecutive patients with active infective endocarditis were studied from 1978 to 1981 . There were 13 male and five female cases (13 to 65 , mean 45 
years). Twelve had class 4 clinical degree of heart failure (New York Heart Association classification) and six were in class 3 . On clinical assessment, 11 patients had aortic regurgitation, one had aortic stenosis, three had mitral regurgitation, and three had aortic and mitral regurgitation. All patients therefore had left sided endocarditis and in all this was the first episode of endocarditis. Active infective endocarditis was diagnosed by varying manifestations, for example fever, changing cardiac murmurs, splenomegaly, haematuria, peripheral embolisation, and petechiae, and by laboratory evidence, including a high erythrocyte sedimentation rate, anaemia, positive blood cultures, and histopathology. In 12 patients the causative organism was isolated preoperatively and in six patients no organisms were cultured (Table 1).

Seven of the 18 patients were known to have had heart murmurs before the development of endocarditis. One patient was a chronic alcoholic and in one patient cardiac surgery was possibly a predisposing factor. No patient suffered from neoplasia or drug addiction. At the time of presentation six patients had had systemic emboli, involving either the cerebral or peripheral arteries, four had heart block (three with first degree atrioventricular block and one with complete heart block not resulting from digoxin), and two patients had had several episodes of severe central chest pain, one of whom had had an acute lateral infarction.
M-mode echocardiography was carried out in all 18 patients using a Smith Kline instruments Ekoline $20 \mathrm{~A}$ system with standard left parasternal views. Immediately after the M-mode echocardiogram, two dimensional echocardiography was performed in 16 patients with a Varian phased array ultrasonograph model V3000 . Long and short axis left parasternal views and four chamber apical or subcostal views were obtained in all 16 patients. An attempt was made to visualise all four valves in each patient. Images were recorded on a Sony video tape recorder for subsequent play back and single frame analysis. Satisfactory echocardiograms were obtained in all 18 patients. Valvular vegetations were detected by $M$-mode echocardiography as shaggy irregular echoes attached to a valve which had unrestricted leaflet excursion (Fig. 1). On two dimensional echocardiography rapidly vibrating echo dense masses attached to valve leaflets were interpreted as vegetations (Fig. 2, 3, 4, and 5). Chamber size and timing of events could be assessed by M-mode echocardiography whereas spatial relation and actual size and morphology of structures were determined by two dimensional echocardiography. Rupture or perforation of an aortic cusp or prolapsing vegetations were suggested by left ventricular outflow tract echoes recorded in diastole and rapidly vibrating diastolic aortic cusp echoes on M-mode echocardiography (Fig. 6). The early closure of a mitral valve was indicated when coaptation of the anterior and posterior leaflets of

Table 1 Clinical, echocardiographic, and surgical findings in 18 patients with active infective endocarditis

\begin{tabular}{|c|c|c|c|c|c|c|c|}
\hline $\begin{array}{l}\text { Case } \\
\text { No. }\end{array}$ & $\begin{array}{l}\text { Age/Sex } \\
(y)\end{array}$ & $\begin{array}{l}\text { Clinical } \\
\text { findings }\end{array}$ & Organism & $\begin{array}{l}\text { Echo } \\
\text { findings }\end{array}$ & $\begin{array}{l}\text { Operative } \\
\text { findings }\end{array}$ & $\begin{array}{l}\text { Operative } \\
\text { procedure }\end{array}$ & $\begin{array}{l}\text { Survived or } \\
\text { died }\end{array}$ \\
\hline $\begin{array}{l}1 \\
2 \\
3\end{array}$ & $\begin{array}{l}\text { 60/F } \\
45 / M \\
27 / M\end{array}$ & $\begin{array}{l}\mathrm{AR} \\
\mathrm{AR} \\
\mathrm{AR}\end{array}$ & $\begin{array}{l}\text { E.coli } \\
\text { Strep. viridans } \\
\text { Staph coag }^{+}\end{array}$ & $\begin{array}{l}\text { AVV,LVOT,EC } \\
\text { AVV,LVOT,EC } \\
\text { AVV,LVOT,EC }\end{array}$ & $\begin{array}{l}\text { AVV,LVOT(PVC) } \\
\text { AVV,LVOT(PVC) } \\
\text { AVV,LVOT(PVC), sinus } \\
\text { to mitral valve }\end{array}$ & $\begin{array}{l}\text { AVR } \\
\text { AVR } \\
\text { AVR, closure of } \\
\text { sinus }\end{array}$ & $\begin{array}{l}\text { S } \\
\text { D }\end{array}$ \\
\hline 4 & $39 / M$ & AR & Staph coag ${ }^{+}$ & AVV,LVOT & $\begin{array}{l}\text { AVV,LVOT(PVC), abscess } \\
\text { in aortic wall }\end{array}$ & $\begin{array}{l}\text { AVR, abscess } \\
\text { debrided }\end{array}$ & $S$ \\
\hline $\begin{array}{l}5 \\
6 \\
7\end{array}$ & $\begin{array}{l}26 / F \\
60 / M \\
54 / M\end{array}$ & $\begin{array}{l}\text { MR } \\
\text { AR } \\
\text { AR,MR }\end{array}$ & $\begin{array}{l}\text { Culture neg } \\
\text { Strep. D } \\
\text { Strep.viridans }\end{array}$ & $\begin{array}{l}\text { MVV,FML } \\
\text { AVV,LVOT } \\
\text { AVV,LVOT }\end{array}$ & $\begin{array}{l}\text { MVV,CR } \\
\text { AVV,LVOT(PVC) } \\
\text { AVV,LVOT(PVC), healed } \\
\text { MVV,CR }\end{array}$ & $\begin{array}{l}\text { MVR } \\
\text { AVR } \\
\text { AVR,MV repair }\end{array}$ & $\begin{array}{l}S \\
S \\
S\end{array}$ \\
\hline $\begin{array}{l}8 \\
9 \\
10 \\
11 \\
12 \\
13 \\
14 \\
15\end{array}$ & $\begin{array}{l}37 / M \\
63 / M \\
59 / F \\
44 / F \\
55 / M \\
54 / F \\
27 / M \\
13 / M\end{array}$ & $\begin{array}{l}\text { AR } \\
\text { AR,MR } \\
\text { AR } \\
\text { AR,MR } \\
\text { MR } \\
\text { MR } \\
\text { AR } \\
\text { AS }\end{array}$ & $\begin{array}{l}\text { Staph coag }^{+} \\
\text {Culture neg } \\
\text { Culture neg } \\
\text { Strep.C } \\
\text { Strep.viridans } \\
\text { Staph coag } \\
\text { Staph coag } \\
\text { Culture neg }\end{array}$ & $\begin{array}{l}\text { No vegetations } \\
\text { AVV,LVOT } \\
\text { AVV,LVOT,EC } \\
\text { AVV,MVV,FML } \\
\text { MVV,FML } \\
\text { No vegetations } \\
\text { AVV,LVOT } \\
\text { AVV, sinus of } \\
\text { Valsalva aneurysm }\end{array}$ & $\begin{array}{l}\text { AVV,MVV } \\
\text { AVV } \\
\text { AVV,LVOT(PVC) } \\
\text { AVV,MVV,CR } \\
\text { MVV,CR } \\
\text { MVV } \\
\text { AVV,LVOT(PVC) } \\
\text { AVV,AMI, sinus of } \\
\text { Valsalva aneursm }\end{array}$ & $\begin{array}{l}\text { AVR } \\
\text { AVR } \\
\text { AVR } \\
\text { AVR,MVR } \\
\text { MVR } \\
\text { MVR } \\
\text { AVR } \\
\text { AVR,SVG to Cx }\end{array}$ & $\begin{array}{l}\text { S } \\
\text { S } \\
\text { S } \\
\text { S } \\
\text { D } \\
\text { D } \\
\text { D }\end{array}$ \\
\hline 16 & $49 / M$ & AR & Culture neg & AVV,LVOT,EC & $\begin{array}{l}\text { AVV,LVOT(PVC),AV ring } \\
\text { infection }\end{array}$ & AVR & D \\
\hline 17 & $34 / M$ & AR & Strep.viridans & AVV,LVOT,EC & AVV,LVOT(PVC),VSD & $\begin{array}{l}\text { AVR, closure of } \\
\text { VSD }\end{array}$ & $\mathbf{S}$ \\
\hline 18 & $65 / M$ & AR & $\begin{array}{l}\text { Culture neg (psittacosis } \\
\text { titre 1:5120) }\end{array}$ & AVV,LVOT & AVV,LVOT(PVC) & AVR & S \\
\hline
\end{tabular}

AR, aortic regurgitation; MR, mitral regurgitation; AS, aortic stenosis; AVV, aortic valvular vegetations; LVOT, left ventricular outflow tract echoes; EC, early closure of the mitral valve; MVV, mitral valve vegetations; FML, flail mitral leaflet; LVOT(PVC), left ventricular outflow tract (prolapsing vegetation and/or cusp); CR, chordal rupture; AMI, acute myocardial infarction; VSD, ventricular septal defect; AVR, aortic valve replacement; MVR, mitral valve replacement; SVG, saphenous vein graft; $\mathrm{Cx}$, circumflex. 


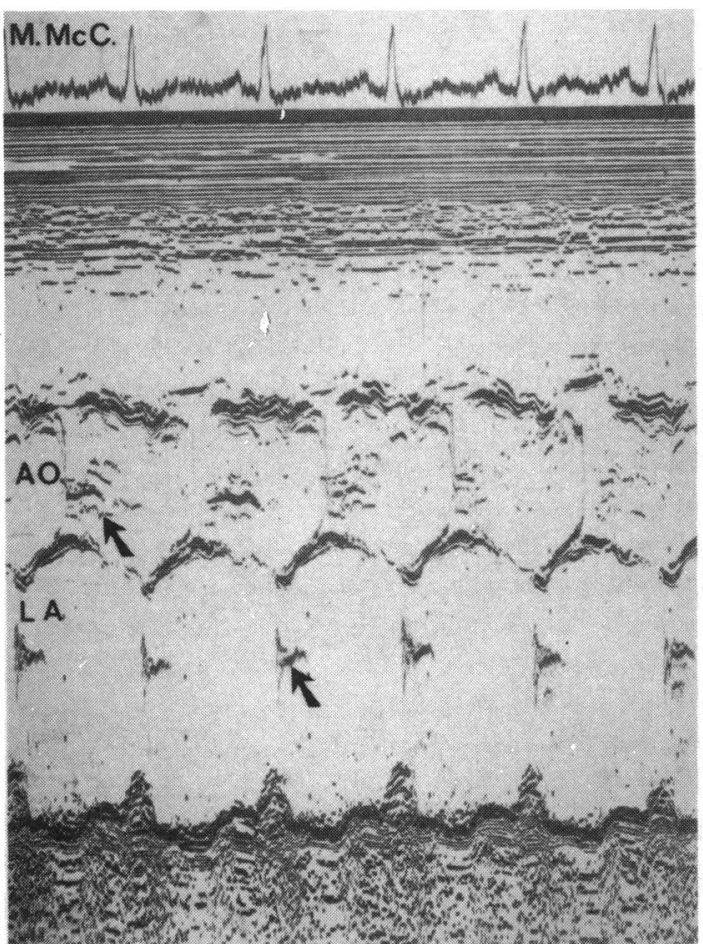

Fig. 1

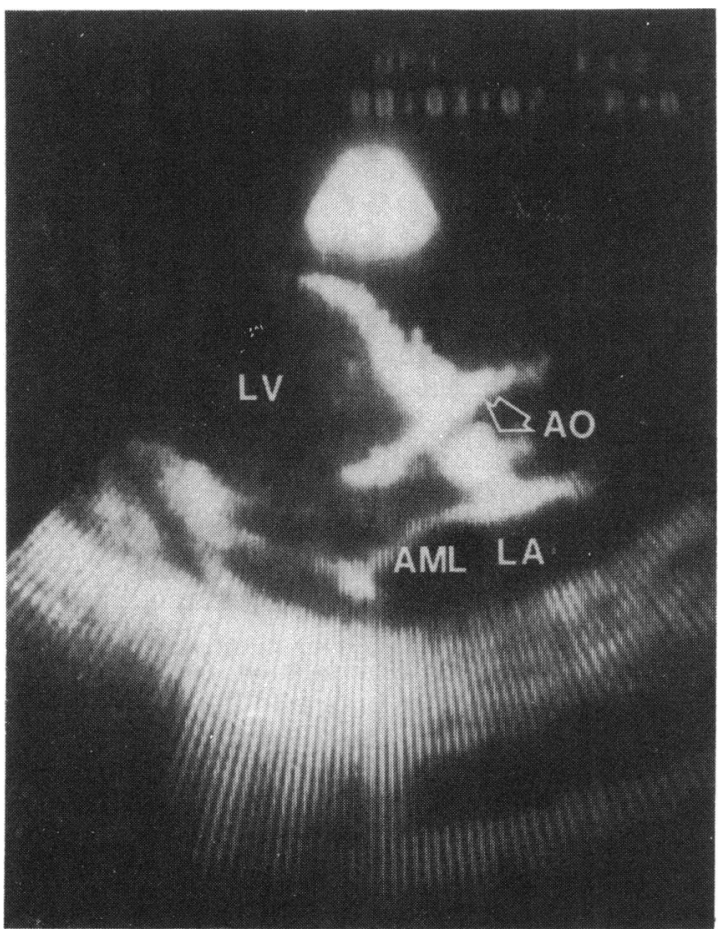

Fig. 2

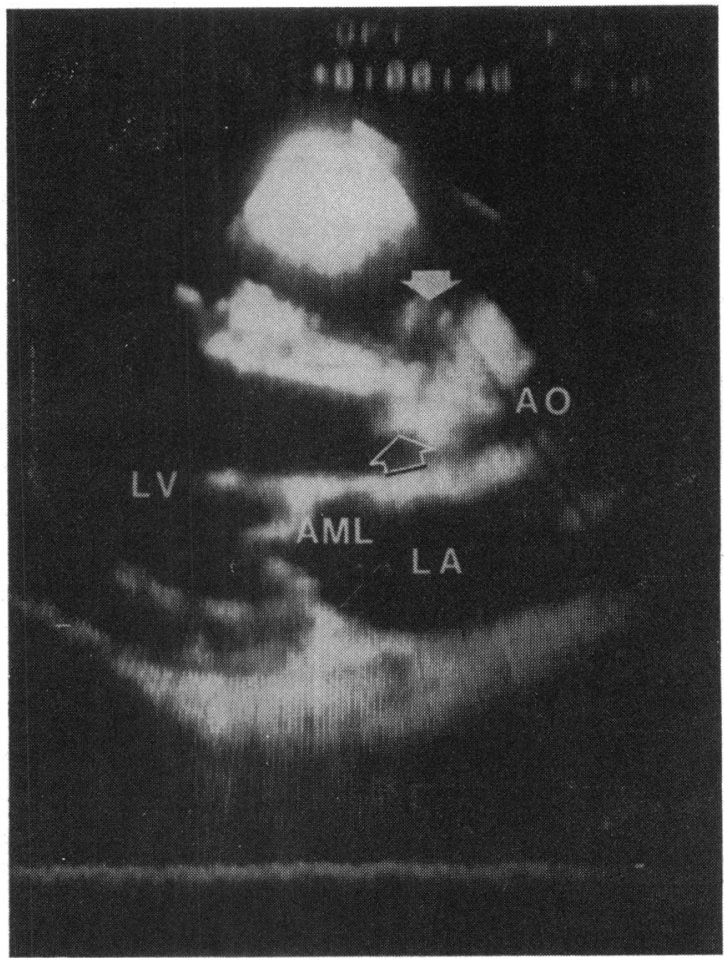

Fig. 3

Fig. 1 M-mode echocardiogram of case 11 showing vegetations (arrow) on the aortic valve in diastole. The echoes (arrow) in the left atrium represent vegetations on the mitral valve prolapsing into the left atrium during systole. AO, aorta; $L A$, left atrium.

Fig. 2 Two dimensional echocardiogram of case 2 in the left parasternal long axis view showing a globular vegetation on the non-coronary cusp of the aortic valve (open arrow). The right coronary cusp with a vegetation attached is seen prolapsing into the left ventricular outflow tract (tongue-like structure). $L V$, left ventricle; $A O$, aorta; $A M L$, anterior mitral leaflet; $L A$, left atrium.

Fig. 3 Two dimensional echocardiogram of case 15 in the left parasternal long axis view with a globular vegetation on the aortic valve (open arrow). Anterior to the aortic valve is an echo-free cavity (closed arrow) which was found at surgery to be a sinus of Valsalva aneurysm. $L V$, left ventricle; $A O$, aorta; $A M L$, anterior mitral leaflet; $L A$, left atrium. 


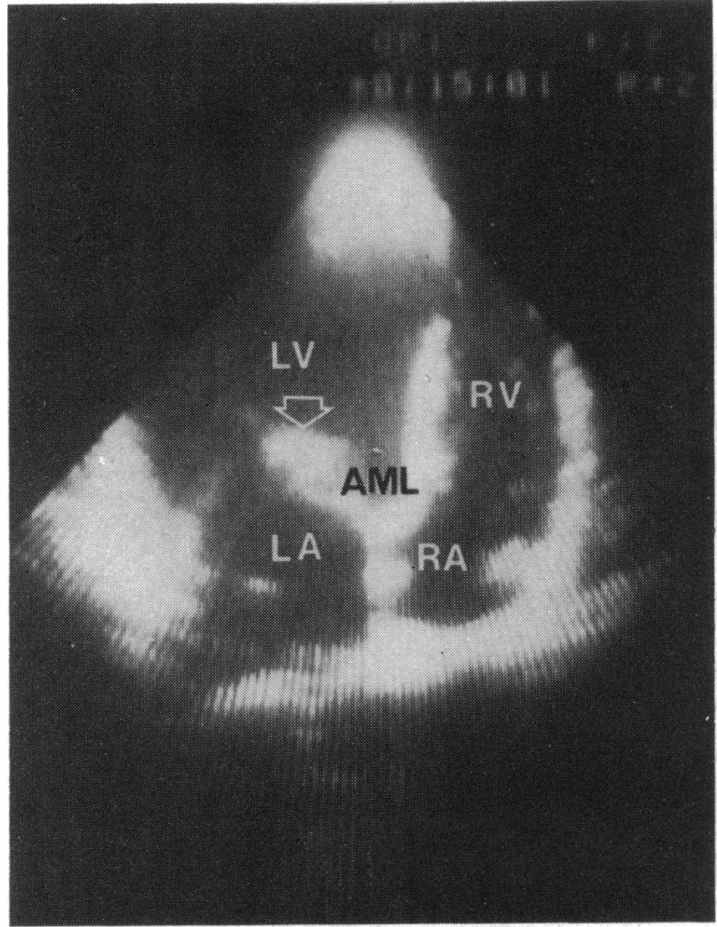

Fig. 4 Two dimensional echocardiogram of case 12 in the apical four chamber view with vegetations attached to the anterior mitral leaflet (open arrow). $L V$, left ventricle; $L A$, left atrium; $R V$, right ventricle; $R A$, right atrium; $A M L$, anterior mitral leaflet.

the mitral valve occurred before the onset of the QRS segment in the absence of prolongation of the PR interval (Fig. 6). This indicated significant aortic regurgitation with a rise in the left ventricular enddiastolic pressure. Mitral valve chordal rupture was present when there was coarse irregular fluttering of either mitral valve leaflet with paradoxical motion of the posterior leaflet and abnormal left atrial echoes (Fig. 7). The average time from the last echo to operation was 15 days (12 patients within seven days).

All patients before operation were receiving appropriate antibiotics. The average time from the onset of symptoms to the start of antibiotic treatment was seven weeks and the mean duration of antibiotic treatment at the time of operation was 36 days. One patient had received antibiotics for only 48 hours at the time of operation; these were given in an attempt to sterilise the circulation before essential valve replacement. At the time of operation blood cultures in all patients except one were negative, but two patients had persistent pyrexia.

The presence of vegetations alone on echocardiography was not an indication per se for operation. ${ }^{10} 11$

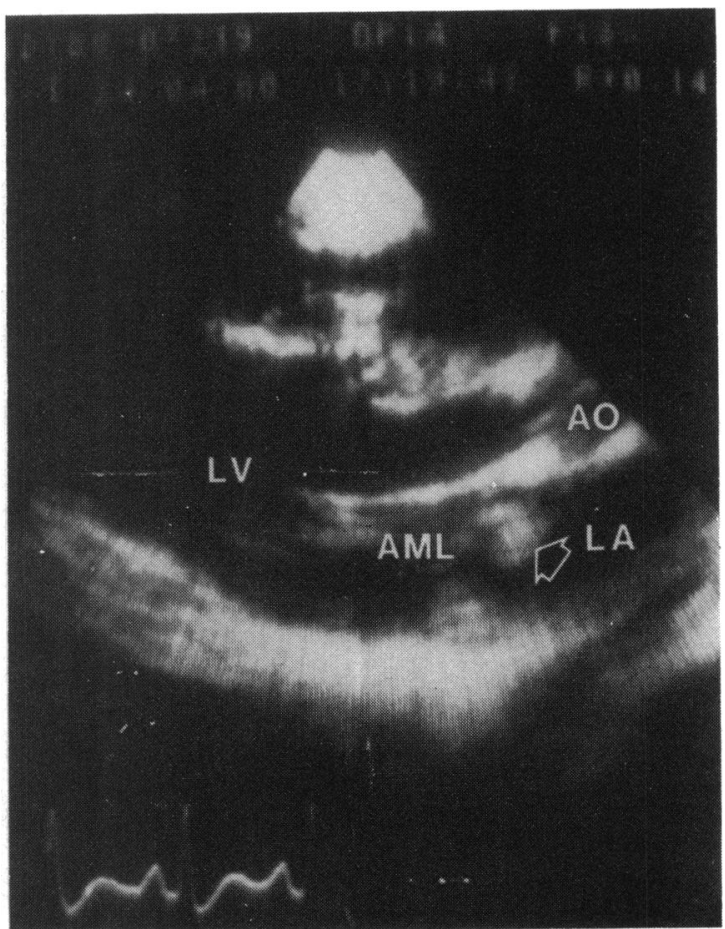

Fig. 5 Two dimensional echocardiogram of case 11 in the left parasternal long axis view with a globular vegetation on the mitral valve prolapsing into the left atrium (open arrow). The vegetation on the aortic valve is not well visualised in this view. $L V$, left ventricle; $A O$, aorta; $A M L$, anterior mitral leaflet; $L A$, left atrium.

Surgical intervention was indicated when patients with severe aortic stenosis or with new or worsening regurgitant murmurs developed left ventricular failure as diagnosed clinically and by chest $x$-ray film which did not respond satisfactorily to diuretics and inotropic therapy. Only six patients underwent cardiac catheterisation before operation. In cases 6 and 13 (mitral Starr-Edwards prosthesis) it was carried out as it was difficult clinically to determine the severity of the lesion. In cases 7, 9, and 11 cardiac catheterisation was carried out because of clinically suspected double valve lesions. In all three patients mitral and aortic regurgitation were haemodynamically significant. In case 15 it was carried out because of severe aortic stenosis, continuing chest pain in the presence of a lateral myocardial infarction, and an echocardiogram suggesting a sinus of Valsalva aneurysm. At the time of catheterisation this patient was found to have severe aortic stenosis with a sinus of Valsalva aneurysm which stretched the mouth of the left coronary artery and constricted the lumen. 


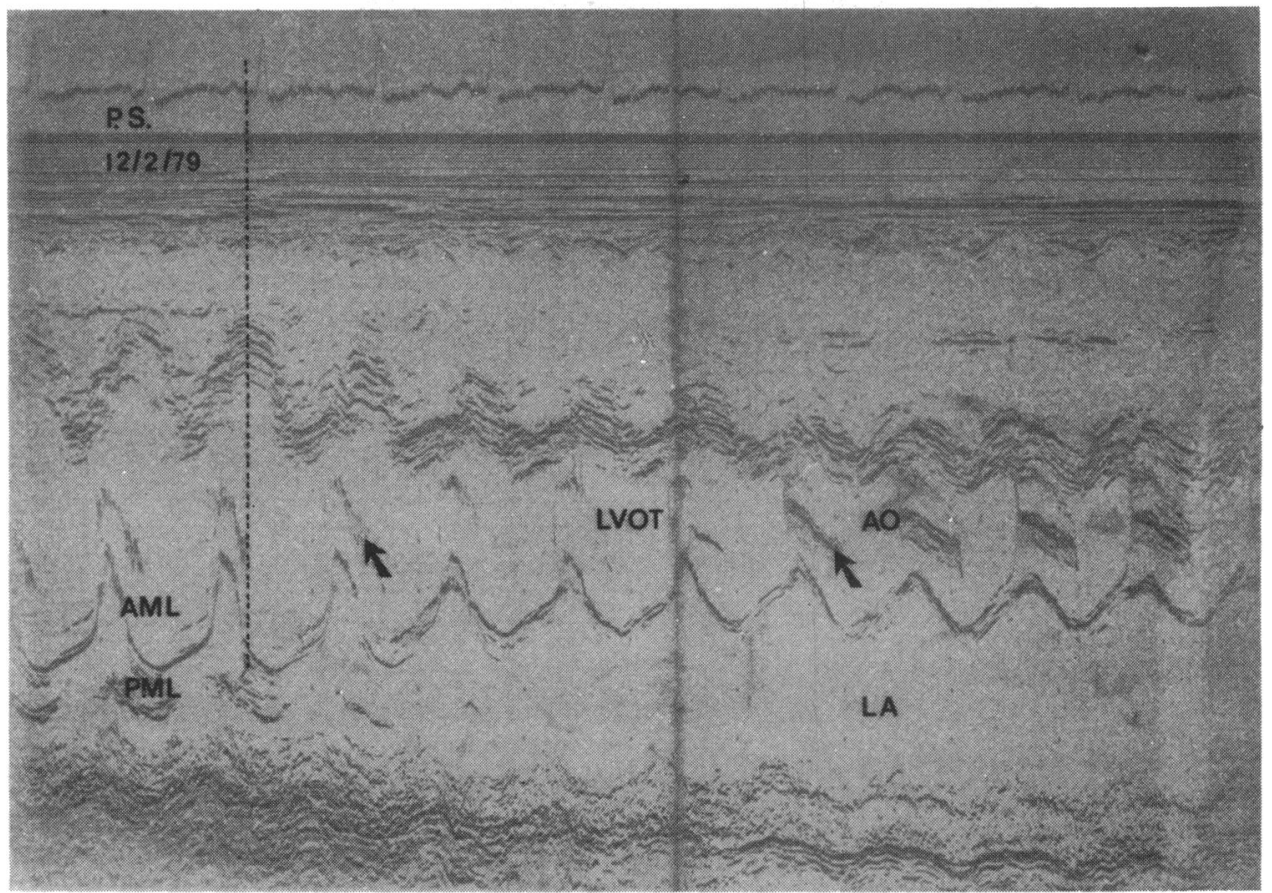

Fig. $6 M$-mode echocardiogram of case 2 showing a scan from the aortic root to the left ventricle. There is a vegetation attached to the aortic valve which prolapses into the left ventricular outflow tract (arrows). The mitral valve closure is premature which indicates a raised left ventricular end-diastolic pressure secondary to aortic regurgitation. $A M L$, anterior mitral leaflet; $P M L$, posterior mitral leaflet; $L V O T$, left ventricular outflow tract; $A O$, aorta; $L A$, left atrium.

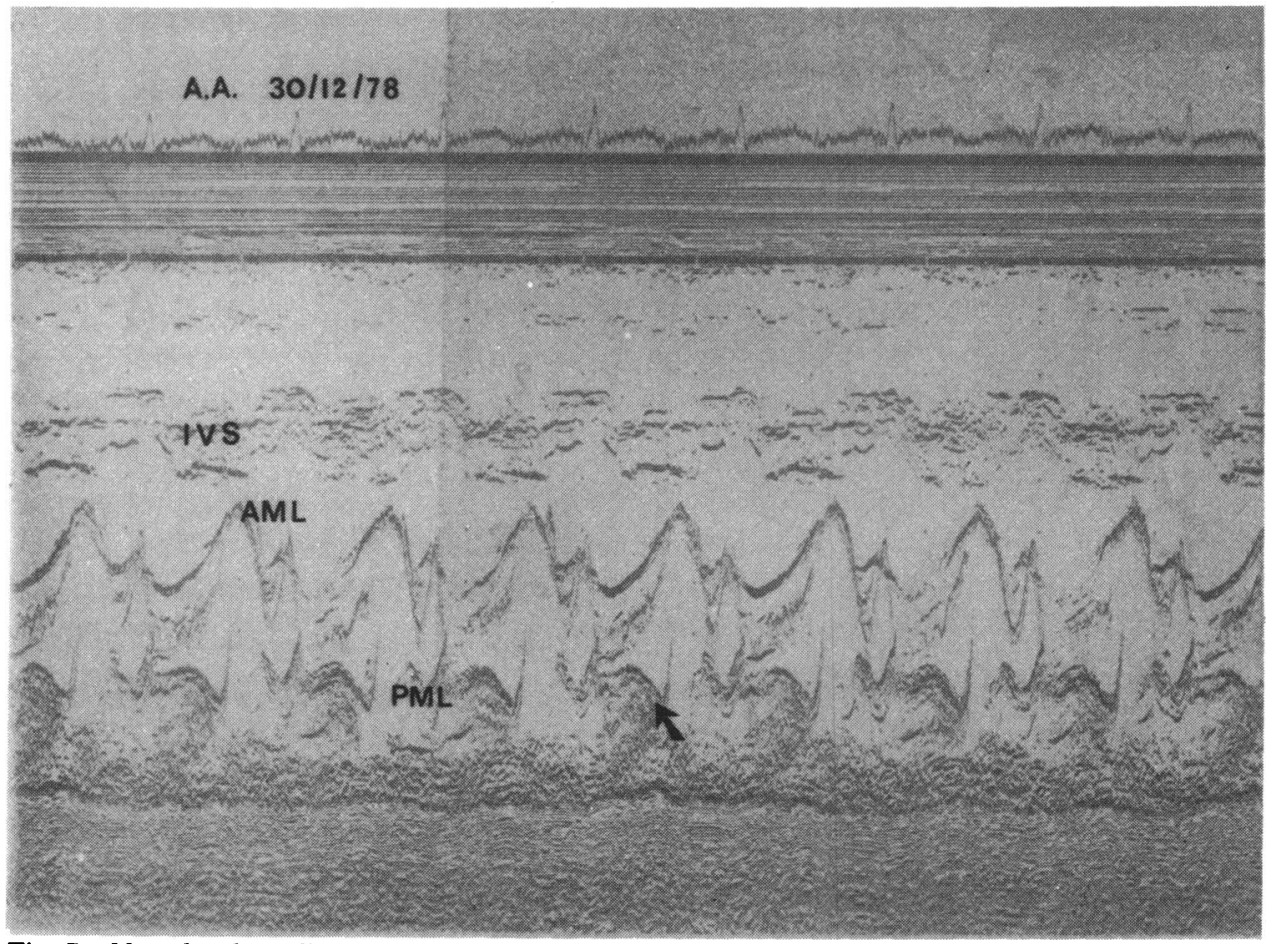

Fig. 7 M-mode echocardiogram of case 12 with a vegetation attached to the posterior mitral leaflet (arrow) which is flail. AML, anterior mitral leaflet; PML, posterior mitral leaflet; IVS, interventricular septum. 


\section{Results}

Echocardiography detected valvular vegetations before operation solely on the aortic valve in 13 patients, on the mitral valve only in two patients, and one patient had both aortic and mitral valve vegetations (Table 1). Two patients (cases 8 and 13) had no vegetations on echocardiography. Case 13 had a mitral StarrEdward's prosthesis. Intially case 15 with aortic stenosis had no vegetations on the aortic valve as seen by echo (Fig. 8). He then developed severe chest pain and left ventricular failure. A second study nine days later showed aortic valvular vegetations and a sinus of Valsalva aneurysm (Fig. 3 and 8). Though cases 13 and 16 did not have two dimensional studies performed, no patient had a negative $M$-mode echocardiogram with valvular vegetations seen on two dimensional study. Twelve of the 13 patients with aortic valve vegetations alone had evidence of valve destruction as indicated by left ventricular outflow tract echoes and in six of these there was early mitral valve closure. Cases 5,11 , and 12 with vegetations by echocardiography on the mitral valve had flail mitral leaflets, but case 11 with double mitral and aortic lesions had vigorous aortic root motion suggesting severe mitral regurgitation.
Operation confirmed aortic vegetations in all 13 patients with vegetations only on the aortic valve detected by echocardiography. All underwent aortic valve replacement and one patient (case 7) also had a mitral valve repair. Two patients with mitral valve vegetations alone by echocardiography had these confirmed at operation and both underwent mitral valve replacement and the one patient with aortic and mitral vegetations confirmed at operation had aortic and mitral valve replacements. Two patients without vegetations recorded by echocardiography had these at operation. In one patient (case 8) the aortic valve was grossly disrupted at the time of operation with a vegetation found on the undersurface and there was also a small vegetation on an otherwise competent mitral valve. Case 13 had vegetations on a mitral StarrEdwards prosthesis. In addition, case 7 had a vegetation on the mitral valve not seen by echocardiogram before operation.

Four patients had unexpected findings at operation and none had undergone cardiac catheterisation. One (case 3) had a sinus extending from the base of an aortic cusp to the mitral valve ring, one (case 4) had an abscess underneath the non-coronary cusp of the aortic valve, another (case 16) had infection within the aortic
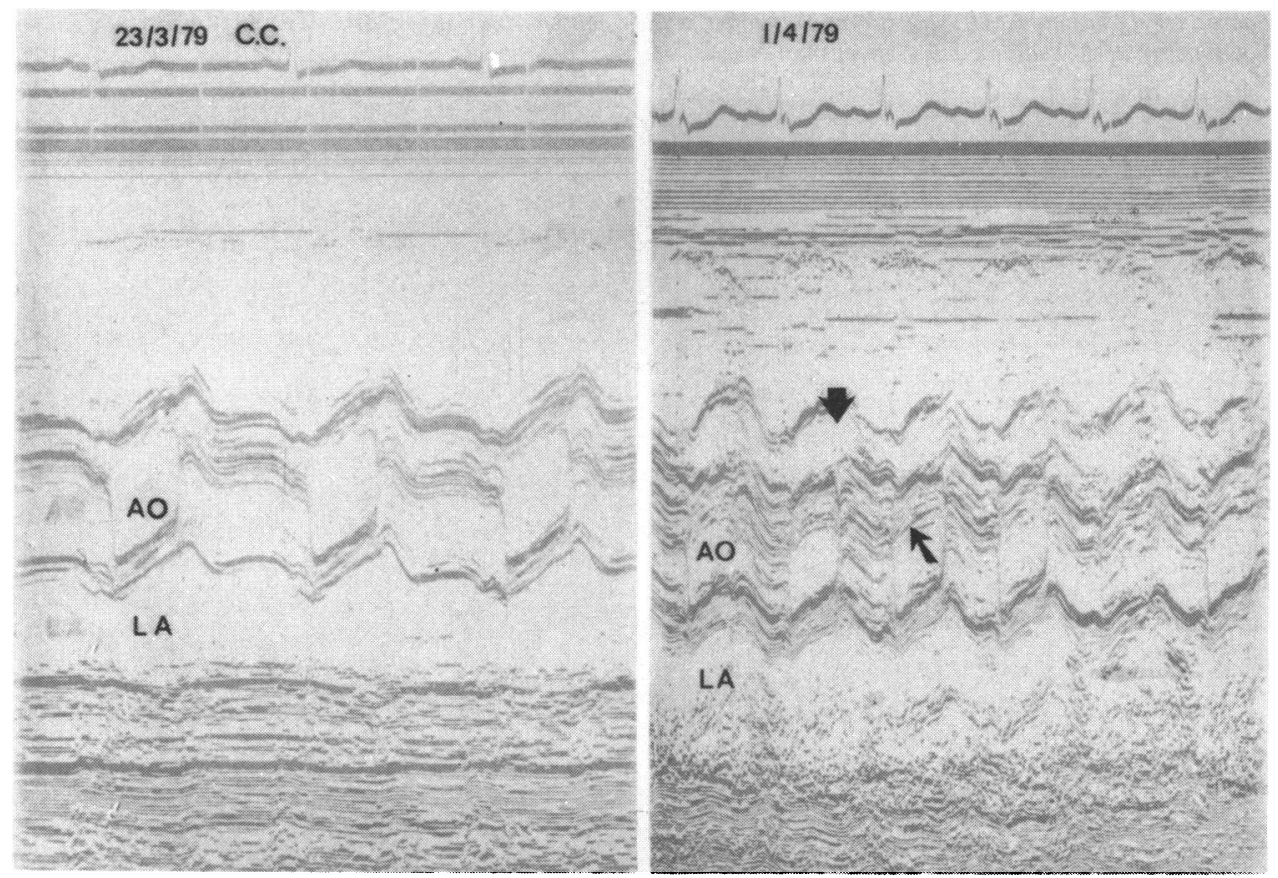

Fig. 8 M-mode echocardiogram of case 15 on admission (left) and nine days later (right). On admission there is eccentric opening and closure of the aortic valve. Nine days later there are aortic valvular vegetations (small arrow) and an echo-free space has occurred in front of the aortic root (large arrow). AO, aorta; LA, left atrium. 
valve ring, and a further patient (case 17) had an aneurysm of the membranous septum with a small ventricular septal defect.

Table 2 relates the valvular lesions to the echocardiographic findings and to those found at operation. While a close correlation is shown between the echocardiographic and surgical findings it confirms that at operation four valves had vegetations not seen by echocardiography. In addition, in four patients presenting with aortic regurgitation alone a sinus, annular erosion, abscess, and a ventricular septal defect not detected by echocardiography were found at operation.

Of the 15 aortic valves replaced, 11 were bicuspid and four were tricuspid. Because of severe damage to the four tricuspid valves it was impossible to ascertain the most likely cause of the underlying disease. Of the four mitral valves replaced, one was rheumatic, one was floppy, one was a Starr-Edwards prosthesis, and one had been normal before endocarditis. Of the three mitral valves found to be abnormal at the time of operation, and which were not replaced, one had chordal rupture associated with a healed vegetation and valvuloplasty was carried out, one patient had a dilated mitral valve ring, and a further patient had a vegetation attached to the mitral valve. Histology of all valves removed confirmed active infection. Of the 19 valves removed, 12 were replaced by a CarpentierEdwards prosthesis, four by a Björk-Shiley, and three by a St. Jude's.

Apart from case 15 who died during the operation from left ventricular dysfunction and acute myocardial infarction, all patients were haemodynamically stable immediately after operation. There were three deaths later during their hospital stay. Case 3 died on the ninth day postoperatively from multiple abscesses, case 13 died on the first day from asystole, and case 16 died on the fifteenth day from hepatic and renal failure. This patient had been a chronic alcoholic. During the period in hospital there was no evidence of continuing infection, and prosthetic dehiscence, paravalvular leaks, and heart block did not occur in the remaining patients. The average course of antibiotics postoperatively was three to six weeks. Follow-up ranged from three to 44 months (mean 22 months). During this time, there was no evidence of reinfection of any of the replaced valves, nor was there any regurgitation.

\section{Discussion}

Although antibiotics have substantially changed the course of the disease in many patients, infective endocarditis still carries a significant mortality mainly because of valvular destruction which results in myocardial failure. ${ }^{12}$ At present, the leading cause of death from infective endocarditis is congestive heart failure developing from acute aortic regurgitation. Since valve replacement was first described in this condition in $1965^{13}$ it is increasingly performed even in the presence of active infection. Often these patients have deteriorated acutely and clinical assessment of the exact valvular lesion can be difficult because of low cardiac output and hypotension.

Although echocardiography is a valuable noninvasive means for the diagnosis of valvular vegetations in patients with endocarditis it has been reported that vegetations are detected in $34 \%$ to $78 \%$ of cases, depending on the size of the vegetations. ${ }^{6}{ }^{14}$ Large valvular vegetations detected by echocardiography are usually associated with a high incidence of heart failure or emboli, which are the most frequent indications for operation. Though in patients with large vegetations it has been considered that operation is inevitable as these patients have a high morbidity and mortality, successful medical treatment has been reported in some. ${ }^{15}$ Vegetations causing valvular destruction are, however, of large size, are diagnosed easily by echocardiography, and in many are associated with haemodynamic complications unresponsive to medical treatment. In this study a close correlation has been shown between valvular vegetations detected by

Table 2 Echocardiographic and surgical findings related to the valvular lesions in 18 patients with active infective endocarditis

\begin{tabular}{|c|c|c|c|c|c|c|c|c|c|c|c|c|c|c|}
\hline \multirow[t]{2}{*}{ Clinical } & \multirow[b]{2}{*}{$\begin{array}{l}\text { No.of } \\
\text { patients }\end{array}$} & \multicolumn{6}{|c|}{ Echocardiography } & \multicolumn{7}{|c|}{ Surgical } \\
\hline & & $\overline{A V V}$ & $L V O T$ & $E C$ & $M V V$ & $F M L$ & $\begin{array}{l}\text { Sinus of } \\
\text { Valsalva } \\
\text { aneurysm }\end{array}$ & $\overline{A V V}$ & $\begin{array}{l}\text { Vegetation } \\
\text { and/or cusp } \\
\text { prolapsing } \\
\text { into LVOT }\end{array}$ & $M V V$ & $\begin{array}{l}\text { Chordal } \\
\text { rupture of } \\
\text { mitral valve }\end{array}$ & $\begin{array}{l}\text { Sinus or } \\
\text { abscess in } \\
\text { aortic wall }\end{array}$ & $V S D$ & $\begin{array}{l}\text { Sinus of } \\
\text { Valsalva } \\
\text { aneurysm }\end{array}$ \\
\hline $\begin{array}{l}\text { AR } \\
\text { AS } \\
\text { MR } \\
\text { AR,MR }\end{array}$ & $\begin{array}{r}11 \\
1 \\
3 \\
3\end{array}$ & $\begin{array}{r}10 \\
1 \\
0 \\
3\end{array}$ & $\begin{array}{r}10 \\
0 \\
0 \\
2\end{array}$ & $\begin{array}{l}6 \\
0 \\
0 \\
0\end{array}$ & $\begin{array}{l}0 \\
0 \\
2 \\
1\end{array}$ & $\begin{array}{l}0 \\
0 \\
2 \\
1\end{array}$ & $\begin{array}{l}0 \\
1 \\
0 \\
0\end{array}$ & $\begin{array}{r}11 \\
1 \\
0 \\
3\end{array}$ & $\begin{array}{r}10 \\
0 \\
0 \\
1\end{array}$ & $\begin{array}{l}1 \\
0 \\
3 \\
2\end{array}$ & $\begin{array}{l}0 \\
0 \\
2 \\
2\end{array}$ & $\begin{array}{l}3 \\
0 \\
0 \\
0\end{array}$ & $\begin{array}{l}1 \\
0 \\
0 \\
0\end{array}$ & $\begin{array}{l}0 \\
1 \\
0 \\
0\end{array}$ \\
\hline
\end{tabular}

AR, aortic regurgitation; AS, aortic stenosis; MR, mitral regurgitation; AVV, aortic valvular vegetations; LVOT, left ventricular outflow tract echoes; EC, early closure of the mitral valve; MVV, mitral valve vegetations; FML, flail mitral leaflet; VSD, ventricular septal defect. 
echocardiography and those found at operation. As $M$-mode and two dimensional echocardiography complement each other, it is not surprising that both $M$ mode and two dimensional echocardiography were equally sensitive in the detection of vegetations in this particular subset of patients. Two patients without vegetations detected by echocardiography were subsequently found to have vegetations at operation. Case 13 was studied by $\mathrm{M}$-mode echocardiography only and the vegetations on the mitral Starr-Edwards valve were not identified. The prosthetic valve is usually so echo producing in itself that it is difficult to identify any additional echoes from possible vegetations. Others have found two dimensional echocardiography more accurate in such cases. ${ }^{16}$ Echocardiography is also useful in assessing left ventricular function and provides valuable information in those with hypotension and low cardiac output. Premature closure of the mitral valve in acute aortic regurgitation is usually an indication for early surgical replacement of the valve. ${ }^{217}$ Early closure of the mitral valve implies a severely volume overloaded left ventricle, and it is thought that when severe aortic regurgitation is of relatively short onset, this results in mitral preclosure. ${ }^{18} 19$ Unfortunately, some patients with acute severe aortic regurgitation do not have this echocardiographic finding.

Echocardiography provided support for the correct anatomical diagnosis in 10 of 11 patients with clinically suspected severe aortic regurgitation and vegetations only on the aortic valve and in two of three patients with severe mitral regurgitation alone. In the three patients with clinically suspected aortic and mitral regurgitation, however, only one patient had double valvular involvement by echocardiography and yet all three had significant mitral and aortic regurgitation by angiography. Here $M$-mode and two dimensional echocardiography detected the sinus of Valsalva aneurysm. Nevertheless, abscesses, annular erosions, sinuses, and small ventricular septal defects are difficult to detect by echocardiography. Of the four in this study, none was detected before operation. It would be doubtful if these would have been picked up by cardiac catheterisation. It has been reported that two dimensional echocardiography is more sensitive than $M$ mode echocardiography in detecting complications of endocarditis. ${ }^{20}{ }^{21}$ It has been stated that aortic root infection should be suspected in the presence of atrioventricular block. ${ }^{22}$ Of the four patients in this study with atrioventricular block, one had infection of the aortic valve ring, one had a ventricular septal defect, but in the remaining two there was no evidence of aortic root infection. Of the two patients with chest pain, one had a sinus of Valsalva aneurysm stretching the mouth of the left coronary artery and the other had a ventricular septal defect with intermittent atrio- ventricular block.

Wilson et al. ${ }^{23}$ have found that replacement of cardiac valves may be carried out successfully in patients with active infective endocarditis even when blood cultures are positive in the immediate preoperative period. The haemodynamic status, however, is the most important factor in determining the timing of valve replacement. While the activity of the infection or the duration of antimicrobial treatment before operation may be of little or no importance in the decision to insert a prosthesis, ideally attempts should be made to eradicate the infection before operation. Antibiotics should be administered until at least the circulation is sterilised but heart failure should not be irreversible. In our patients we feel that the timing was critical in determining long-term survival and echocardiography allowed repeated investigation to determine the optimal time haemodynamically without the risks of left heart catheterisation. ${ }^{22}$

Although Welton et al. ${ }^{24}$ have reported catheterisation in 35 patients during the active phase of endocarditis without embolic or haemodynamic deterioration, cardiac catheterisation must carry an increased risk during this phase as valvular vegetations are friable and systemic embolisation is part of the natural history of the disease. Frequently severe haemodynamic decompensation may increase the risk of complications during cardiac catheterisation. In these 18 patients one third had had systemic emboli at the time of presentation and others have reported a higher incidence. ${ }^{8}$ Our study indicates that cardiac catheterisation is unnecessary in many of these patients during the acute phase. It should be considered when the echocardiographic studies are not technically adequate, when double valvular lesions, coronary artery lesions and fistulae are suspected, and in the presence of prosthetic valve endocarditis. These criteria should identify those patients where the benefits obtained from cardiac catheterisation outweigh the increased risk of the procedure in infective endocarditis.

In patients with left ventricular failure caused by severe valvular disease the clinical findings along with echocardiography provide a satisfactory means of preoperative evaluation. Though our series of 18 patients is small and includes only patients with left sided endocarditis, our study indicates that echocardiography can provide valuable preoperative data when included with the total clinical assessment of the patient. This applies particularly to those cases where clinical and echocardiographic assessment suggest single valve involvement.

\section{References}

1 Wann LS, Dillon JC, Weyman AE, Feigenbaum $H$. Echocardiography in bacterial endocarditis. N EnglF Med 1976; 295: 135-9. 
2 Mintz GS, Kotler MN, Segal BL, Parry WR. Survival of patients with aortic valve endocarditis. Arch Intern Med 1979; 139: 862-6.

3 Young JB, Welton DE, Raizner AE, et al. Surgery in active infective endocarditis. Circulation 1979; 60, suppl I: 77-81.

4 Richardson JV, Karp RB, Kirklin JW, Dismukes WE. Treatment of infective endocarditis. A 10-year comparative analysis. Circulation 1978; 58: 589-97.

5 Dinubile MJ. Surgery in active endocarditis. Ann Intern Med 1982; 96: 650-9.

6 Davis RS, Strom JA, Frishman W, et al. The demonstration of vegetations by echocardiography in bacterial endocarditis. An indication for early surgical intervention. Am F Med 1980; 69: 57-63.

7 Dillon JC, Feigenbaum H, Konecke LL, Davis RH, Chang S. Echocardiographic manifestations of valvular vegetations. Am Heart f 1973; 86: 698-704.

8 Stewart JA, Silimperi D, Harris P, Wise NK, Fraker TD Jr, Kisslo JA. Echocardiographic documentation of vegetative lesions in infective endocarditis: clinical implications. Circulation 1980; 61: 374-80.

9 Wann LS, Hallam CC, Dillon JC, Weyman AE, Feigenbaum $H$. Comparison of $M$-mode and crosssectional echocardiography in infective endocarditis. Circulation 1979; 60: 728-33.

10 Sheikh MU, Covarrubias EA, Ali N, Sheikh NM, Lee WR, Roberts WC. M-mode echocardiographic observations in active bacterial endocarditis limited to the aortic valve. Am Heart F 1981; 102: 66-75.

11 Berger M, Gallerstein PE, Benhuri P, Balla R, Goldberg E. Evaluation of aortic valve endocarditis by twodimensional echocardiography. Chest $1981 ; 80$ : 61-7.

12 Anonymous. Infective endocarditis (editorial). $\mathrm{Br} \mathrm{Med} \mathrm{J}$ 1981; 282: 677-8.

13 Wallace AG, Young WG Jr, Osterhout S. Treatment of acute bacterial endocarditis by valve excision and replacement. Circulation 1965; 31: 450-3.

14 Strom J, Becker R, Davis R, et al. Echocardiographic and surgical correlations in bacterial endocarditis. Circulation 1980; 62, suppl I: 164-7.

15 Sheikh MU, Covarrubias EA, Ali N, Lee WR, Sheikh NM, Roberts WC. M-mode echocardiographic obser- vations during and after healing of active bacterial endocarditis limited to the mitral valve. Am Heart 7 1981; 101: 37-45.

16 Martin RP, Meltzer RS, Chia BL, Stinson EB, Rakowski H, Popp RL. Clinical utility of two dimensional echocardiography in infective endocarditis. Am $\mathcal{F}$ Cardiol 1980; 46: 379-85.

17 Mann T, McLaurin L, Grossman W, Craige E. Assessing the hemodynamic severity of acute aortic regurgitation due to infective endocarditis. $N$ Engl F Med 1975; 293: 108-13.

18 DeMaria AN, King JF, Salel AF, Caudill CC, Miller RR, Mason DT. Echography and phonography of acute aortic regurgitation in bacterial endocarditis. Ann Intern Med 1975; 82: 329-35.

19 Botvinick EH, Schiller NB, Wickramasekaran R, Klausner SC, Gertz E. Echocardiographic demonstration of early mitral valve closure in severe aortic insufficiency. Circulation 1975; 51: 836-47.

20 Mintz GS, Kotler MN, Segal BL, Parry WR. Comparison of two-dimensional and M-mode echocardiography in the evaluation of patients with infective endocarditis. $A m \mathcal{F}$ Cardiol 1979; 43: 738-44.

21 Wong CM, Oldershaw P, Gibson DG. Echocardiographic demonstration of aortic root abscess after infective endocarditis. Br Heart $\mathcal{F} 1981$; 46: 584-6.

22 Mills J, Abbott J, Utley JR, Ryan C. Role of cardiac catheterization in infective endocarditis. Chest 1977; 72: 576-82.

23 Wilson WR, Danielson GK, Giuliani ER, Washington JA II, Jaumin PM, Geraci JE. Valve replacement in patients with active infective endocarditis. Circulation 1978; 58: 585-8.

24 Welton DE, Young JB, Raizner AE, et al. Value and safety of cardiac catheterization during active infective endocarditis. Am f Cardiol 1979 44: 1306-10.

Requests for reprints to Dr A A J Adgey, Regional Medical Cardiology Centre, Royal Victoria Hospital, Grosvenor Road, Belfast, BT12 6BA, Northern Ireland. 